\title{
ERS statement on harmonised standards for lung cancer registration and lung cancer services in Europe
}

\author{
Anna L. Rich ${ }^{1}$, David R. Baldwin ${ }^{1}$, Paul Beckett ${ }^{2}$, Thierry Berghmans ${ }^{3}$, \\ Jeanette Boyd ${ }^{4}$, Corinne Faivre-Finn ${ }^{5}$, Francoise Galateau-Salle ${ }^{6}$, \\ Fernando Gamarra ${ }^{7}$, Bogdan Grigoriu ${ }^{3}$, Niels-Christian G. Hansen ${ }^{8}$, \\ Georgia Hardavella 9,10, Erik Jakobsen ${ }^{11}$, Dragana Jovanovic ${ }^{12}$, \\ Assia Konsoulova ${ }^{13}$, Gilbert Massard ${ }^{14}$, John McPhelim ${ }^{15}$, Anne-Pascale Meert ${ }^{3}$, \\ Robert Milroy ${ }^{16}$, Luciano Mutti ${ }^{17}$, Marianne Paesmans ${ }^{18}$, Michael D. Peake ${ }^{19,20}$, \\ Paul Martin Putora ${ }^{21,22}$, Dirk K.M. de Ruysscher ${ }^{23,24}$, Jean-Paul Sculier ${ }^{3}$, \\ Arnaud Scherpereel ${ }^{25}$, Dragan R. Subotic ${ }^{26}$, Paul Van Schil ${ }^{27}$ and \\ Torsten Gerriet Blum ${ }^{28}$
}

@ERSpublications

Written by Europeans for Europeans, this minimum dataset and manual for lung cancer services will help to improve standards for our patients http://ow.ly/6qa630mm5bz

Cite this article as: Rich AL, Baldwin DR, Beckett P, et al. ERS statement on harmonised standards for lung cancer registration and lung cancer services in Europe. Eur Respir J 2018; 52: 1800610 [https://doi.org/ $10.1183 / 13993003.00610-2018]$.

ABSTRACT The European Respiratory Society (ERS) task force for harmonised standards for lung cancer registration and lung cancer services in Europe recognised the need to create a single dataset for use in pan-European data collection and a manual of standards for European lung cancer services.

The multidisciplinary task force considered evidence from two different sources, reviewing existing national and international datasets alongside the results of a survey of clinical data collection on lung cancer in 35 European countries. A similar process was followed for the manual of lung cancer services, with the task force using existing guidelines and national or international recommendations for lung cancer services to develop a manual of standards for services in Europe.

The task force developed essential and minimum datasets for lung cancer registration to enable all countries to collect the same essential data and some to collect data with greater detail. The task force also developed a manual specifying standards for lung cancer services in Europe.

Despite the wide variation in the sociopolitical landscape across Europe, the ERS is determined to encourage the delivery of high-quality lung cancer care. Both the manual of lung cancer services and the minimum dataset for lung cancer registration will support this aspiration.

Published online Dec 20, 2018; republished May 15, 2019 with a correction to a typographical error in one of the author names (A. Scherpereel).

This article has supplementary material available from erj.ersjournals.com

This document was endorsed by the ERS Science Council and Executive Committee on September 19, 2018.

Received: March 292018 | Accepted after revision: July 032018

Copyright OERS 2018 
Affiliations: 'Dept of Respiratory Medicine, Nottingham University Hospitals NHS Trust, Nottingham, UK. ${ }^{2}$ Dept of Respiratory Medicine, Derby Teaching Hospitals NHS Foundation Trust, Derby, UK. ${ }^{3}$ Intensive Care and Thoracic Oncology, Institut Jules Bordet, Université Libre de Bruxelles, Brussels, Belgium. ${ }^{4}$ European Lung Foundation, Sheffield, UK. ${ }^{5}$ Division of Cancer Sciences, University of Manchester and The Christie NHS Foundation Trust, Manchester, UK. ${ }^{6}$ Dept of Biopathology, MESOPATH/MESOBANK Cancer Center Leon Berard, Lyon, France. ${ }^{7}$ Sektion Pneumologie, Klinikum St. Elisabeth, Straubing, Germany. ${ }^{8}$ Dept of Respiratory Medicine, Odense University Hospital, Odense, Denmark. 'Dept of Respiratory Medicine, King's College Hospital London, London, UK. ${ }^{10}$ Dept of Respiratory Medicine and Allergy, King's College London, London, UK. ${ }^{11}$ Dept of Thoracic Surgery, Odense University Hospital, Odense, Denmark. ${ }^{12}$ University Hospital of Pulmonology, Clinical Center of Serbia, Belgrade, Serbia. ${ }^{13}$ Medical Oncology Clinic, University Hospital "Sveta Marina", Varna, Bulgaria. ${ }^{14}$ Service de Chirurgie Thoracique, Hôpitaux Universitaires de Strasbourg Strasbourg, France. ${ }^{15}$ Hairmyres Hospital, NHS Lanarkshire, East Kilbride, UK. ${ }^{16}$ Scottish Lung Cancer Forum, Glasgow Royal Infirmary, Glasgow, UK. ${ }^{17}$ Biomedical Research Centre, University of Salford, Salford, UK. ${ }^{18}$ Data Centre, Institut Jules Bordet, Université Libre de Bruxelles, Brussels, Belgium. ${ }^{19}$ University of Leicester, Leicester, UK. ${ }^{20}$ University College London Hospitals, London, UK. ${ }^{21}$ Dept of Radiation Oncology, Kantonsspital St Gallen, St Gallen, Switzerland. ${ }^{22}$ Dept of Radiation Oncology, University of Bern, Bern, Switzerland. ${ }^{23}$ Maastricht University Medical Center, Dept of Radiation Oncology (Maastro Clinic), GROW School for Oncology and Developmental Biology, Maastricht, The Netherlands. ${ }^{24}$ Radiation Oncology, KU Leuven, Leuven, Belgium. ${ }^{25}$ Pulmonary and Thoracic Oncology, Université de Lille, Inserm, CHU Lille, Lille, France. ${ }^{26}$ Dept of Thoracic Surgery, University Hospital, Basel, Switzerland. ${ }^{27}$ Dept of Thoracic and Vascular Surgery, Antwerp University Hospital, Edegem (Antwerp), Belgium. ${ }^{28}$ Klinik für Pneumologie, Lungenklinik Heckeshorn, HELIOS Klinikum Emil von Behring, Berlin, Germany.

Correspondence: Anna L. Rich, Dept of Respiratory Medicine, Nottingham University Hospitals NHS Trust, City Campus, Hucknall Road, Nottingham, NG5 1PB, UK. E-mail: anna.richanottingham.ac.uk

\section{Introduction}

Lung cancer is the second most common cancer in men and women in Europe and the commonest cause of cancer-related death [1]. Europe accounts for a quarter of all lung cancer deaths globally despite representing an eighth of the world's population [2]. Recent advances in techniques for diagnosis, staging and treatment have seen a modest improvement in outcomes and there is hope that further developments in molecular targeted treatments and immunotherapy, as well as potential combination treatments and the expected implementation of low radiation dose computed tomography (CT) screening, will further improve outcomes [3]. However, improvements in clinical services vary greatly across Europe owing to a variety of organisational, economic and sociopolitical factors. To help drive the adoption of best clinical practice that is delivered more equitably, an agreed service specification and agreement on the metrics by which the service can be measured are needed. This requires a description of the standards for lung cancer services and a uniform cancer registration system to measure the activity.

In 2015, the European Respiratory Society (ERS) approved a task force to create a pan-European thoracic oncology dataset and develop internationally agreed standards for European thoracic oncology centres. The membership of the task force was derived from a previously successful task force on quality management in lung cancer and hence includes a multidisciplinary group with a keen interest in the development of harmonised international standards. The two main aims of this group were to develop a pan-European dataset and a manual of standards for lung cancer services in Europe.

\section{Lung cancer registration in Europe: the need for a pan-European dataset}

Cancer data collection in Europe began in the 1950s with the establishment of cancer registries. However, it was not until the 1990s that they were widespread enough to allow meaningful comparative research to be done. The EUROCARE series of large-scale publications demonstrated the variation in epidemiological features and outcomes in a large number of European countries [4, 5]. These publications have sparked interest from the public and politicians alike, and they have been the catalyst for many developments at the national and international level to improve outcomes for individuals with cancer. The number of cancer registries involved in EUROCARE studies has grown, and the level of population coverage improved, but there remain large parts of Europe that are not accounted for in these studies [6]. Data items and their definitions are not universally agreed, and so comparisons cannot always be standardised. Furthermore, few registries collect sufficient clinical details at the individual patient level to support meaningful comparisons of outcome within and between countries.

The strategy of the European Union (EU) against cancer has focused on the importance of cancer registration. The EU has funded several initiatives, including the European Action Against Cancer Programme (1985-2008), the European Partnership for Action Against Cancer (EPAAC) (2009-2014) [7] and the EU Cancer Control Joint Action (CANCON) [8]. The European Network of Cancer Registries (ENCR) was set up in 1990 as a joint venture with several other international cancer research groups to promote the quality of cancer registration across Europe and the use of these data for clinical and public 
health research. The ENCR has published a minimum dataset for cancer registries as well as an optional dataset [9]. These are generic for every cancer rather than being lung cancer specific.

\section{Lung cancer services in Europe: the need for harmonised international standards}

Europe has a diverse healthcare structure generated by diversity in social, political and economic factors. However, in thoracic oncology, the aim of the healthcare system is to provide the best standard of care to provide patients with the best outcomes. In general, countries have a combination of large centres, usually based in large hospitals with a concentration of expertise and technology, and smaller healthcare providers, with less equipment and less comprehensive services. Some countries have additional primary care services that play a crucial role throughout the lung cancer pathway. A previous ERS task force report described the differences in the healthcare infrastructure for 38 European countries [10]. The diversity across Europe has undoubtedly contributed to the variation in healthcare outcomes, and agreement on the standards that centres should adopt is one way to mitigate this effect.

\section{Methods}

Group composition

The task force was chaired by Anna Rich and Torsten Blum with a further 25 members from nine countries around Europe. All members have a specialist interest in lung cancer, and represent different aspects of the multidisciplinary team (MDT): pathology, pulmonology, radiation oncology, medical oncology, thoracic surgery, palliative care, a lung cancer nurse specialist (LCNS) and a medical statistician. Patients' views were represented through the lung cancer patient advisory group (PAG) of the European Lung Foundation (ELF).

\section{Conflicts of interest}

All task force members declared and signed conflict of interest statements at the beginning of the project and updated them at project finalisation.

\section{Working methods}

The task force met at face-to-face meetings held at the ERS congress in Amsterdam in September 2015. The aims and objectives of the project were discussed and agreed, and the proposal for two work streams, led by Anna Rich (minimum dataset) and Torsten Blum (manual for lung cancer services), was ratified. Further face-to-face meetings were held in London in May 2016, at the ERS congress in London in September 2016 and in London in March 2017. A final face-to-face meeting was held at the congress in Milan in September 2017 when the final report was discussed in detail. Conference calls and e-mail correspondence were also used to discuss and amend details within the minimum dataset and the manual of lung cancer services as they were developed.

\section{Review of existing datasets}

Datasets in use or in development were reviewed before and during meetings of the task force. These included the work from an allied project [11] as well as national datasets from countries represented on the task force. Supplement 1.1 reports the datasets reviewed and key facts regarding their development. The aim was to understand the similarities and differences in data collected and to derive a harmonised dataset that would encompass, as far as possible, existing data collected, as well as extending to a minimum dataset. Existing datasets from ENCR and the International Consortium for Health Outcome Measures (ICHOM) were used as reference datasets $[9,12]$. These were chosen for their comprehensiveness and because they were developed by international groups. However, the task force identified these datasets as being too detailed and ambitious to be applied as harmonised standards in Europe, where a more pragmatic approach is needed.

Membership of the task force included professionals who have considerable experience in developing and implementing national audits. This expertise was used to make realistic proposals for a European dataset. The data items were chosen on the basis of consensus opinion, with a majority of $>90 \%$ agreement.

\section{Evidence search and review of existing manuals}

Members of the task force performed a narrative search of existing manuals for lung cancer services. This search included relevant websites or printed publications of related international societies and other stakeholders, and national-level publications accessible to task force members (supplement 1.2). Given that a systematic search on the national level was beyond the means of this task force, the group accepted a potential selection bias based on a limitation to only those European countries represented on the task force. 
During the course of this task force, Torsten Blum browsed repeatedly through the websites of the named international societies and other stakeholders for substantial online or referenced printed publications. Evidence retrieved from this narrative search as well as from reports identified by other task force members was amalgamated (by T. Blum) and then discussed during task force meetings. All searches on the international level were last updated in November 2017 (by T. Blum). Detailed results are provided in supplement 1.2.

The previous ERS task force on quality management in lung cancer care revealed that there are more than 150 lung cancer guidelines worldwide, and more than 80 within Europe [10]. There was significant variation in the quality of these guidelines, in terms of the underlying evidence used, the specific aspects of the lung cancer pathway being addressed and the publication date. Only a minority of these guidelines addressed the infrastructure and pathway processes in any meaningful way that would allow them to inform our aspired manual of standards for lung cancer services.

The task force did not perform systematic evidence searches in medical databases on its own, but used relevant results from a Grading of Recommendations Assessment, Development and Evaluation (GRADE)-based systematic review of the literature on quality management in lung cancer with a focus on the impact of defined lung cancer services. This was the subject of a parallel ERS task force that will be published in full separately. Overall, published material was found to be very limited and of low quality.

An agreed list of standards for lung cancer services in Europe was developed during task force meetings and interim discussion. The recommended manual of standards for lung cancer services is based on a review of available evidence and is complemented by the inclusion of patient perspectives as well as the clinical experience of the task force members.

\section{The European Lung Foundation patient advisory group}

The ELF lung cancer PAG was established to support a range of research activities relating to lung cancer. The PAG is made up of people who have received a diagnosis of lung cancer (either undergoing treatment or survivors), caregivers of people with lung cancer and representatives of lung cancer patient organisations. Every member responded to an advert on the ELF website and was interviewed informally by phone or Skype before being accepted onto the PAG. The PAG allows individuals to self-select which projects they can most usefully support, based on their experience and interests, and also allows them to withdraw at any time if health issues arise.

The task force considered it essential that the dataset and manual created be meaningful to patients. ELF staff member Jeanette Boyd was invited to attend task force meetings and facilitate the gathering of views from PAG members regarding the development of both the pan-European dataset and the manual for lung cancer services. Five members provided feedback on the dataset (four patients and one patient organisation representative; from Czech Republic, Italy and UK) and four members provided feedback on the manual of lung cancer services (two patients, one caregiver and one patient organisation representative; from Denmark, Ireland, Poland and the UK). Views were gathered by sharing documentation via email and requesting feedback. Jeanette Boyd collated and analysed the feedback using a qualitative approach and presented this to the task force for consideration. In addition, Torsten Blum conducted semi-structured telephone interviews with PAG members for feedback relating to the manual of lung cancer services.

\section{Manuscript preparation}

Anna Rich and Torsten Blum wrote the task force final report, with editing and some modification provided by David Baldwin. Michael Peake was invited to write the subsection regarding the National Lung Cancer Audit of England and Wales, as an external co-author. The paper was then circulated to all members of the task force and revisions made by Anna Rich. The statement paper and supplements were reviewed, edited and approved by all members of the task force before submission.

\section{Part 1. Development of a pan-European lung cancer dataset}

Two national lung cancer datasets stood out as exemplars of data completeness and the use of data to drive improvement in services and outcomes; they are described below.

\section{Drivers, development and implementation of two national lung cancer audit programmes: Denmark and England \\ Drivers}

The two main drivers behind the development of both of these well-established audit programmes were 1) preliminary comparative data in the 1990s suggesting poorer outcomes than in other countries and 2) evidence for unwarranted variation in clinical practice. EUROCARE-1 reported 5-year survival in lung cancer in England and Denmark as being $<8 \%$ [4]. This prompted the Royal College of Physicians of 
London, with funds provided by the English Government, to sponsor a snapshot audit [13]. This audit, involving 52 hospitals between 1995 and 1996, showed large variations in the care of lung cancer patients and led to efforts to establish a longer term, population-based lung cancer audit programme. In Denmark, similar variations were apparent. The healthcare system was organised so that diagnostics and treatment was provided by a large number of hospital departments with very different approaches to the disease. The Danish Lung Cancer Group (DLCG) was formed with the primary aim of improving the clinical management and survival of Danish lung cancer patients. A secondary aim was to produce a platform for lung cancer research. The DLCG produced national guidelines for the management of lung cancer [14] and adopted a strategy to implement the guidelines and concurrently monitor the implementation by reporting to a national registry, known as The Danish Lung Cancer Registry (DLCR).

\section{Development and implementation}

The Danish Lung Cancer Registry

The DLCR started in 2000 and now contains data on 70000 patients. Between 2000 and 2012, inclusion of patients relied on clinicians identifying and reporting patients to the DLCR, but since 2013 patients have been identified from the first diagnostic codes for lung cancer in the Danish National Patient Registry (DNPR). The latter helped improve data completeness and reduce the workload for clinicians. Participation has since become mandatory by law, so data completeness is now $>95 \%$ of new cases. The basic database is derived from the DNPR and the Danish Pathology Register and includes procedures and treatment. This is supplemented and validated online by clinicians to form the DLCR. All departments involved in the diagnosis and treatment of lung cancer in Denmark are responsible for the validation and supplementation of data [15].

The database contains demographic and patient characteristics and details of treatment, including surgery, type and duration of chemotherapy, and type and duration of radiation. Patients' vital statuses are derived monthly from the Danish Civil Registration System and age at diagnosis confirmed from the personal identification number. During the 18 years of data collection in the DLCR, major improvements in treatment outcomes have been recorded [16]. The DLCR has developed a number of indicators using scientific evidence and the national guideline recommendation. The indicators are reported monthly and annually to all participating departments, hospitals and healthcare authorities. A comprehensive system of audits ensures that differences in quality measures and failure to meet standards are evaluated.

A number of publications based on the DLCR have appeared since 2009, documenting the effects of a national registry. The two major lessons that have been learned are first that high data quality and completeness is essential to ensure that clinicians will work with the data and results from the database. Meaningful audit depends on the accuracy and credibility of data; only once clinicians are convinced of this is it possible to shift the focus from data quality to the findings. Second, it is important that hospital and regional management are involved in the implementation process to facilitate the changes in services and clinical practice that are recommended by the findings of the audit [17]. Centralisation in Denmark is traditionally met with resistance from local stakeholders, and the involvement of management has played a central role. The DLCR has shown that regional differences have decreased as the number of departments involved in treating lung cancer patients has halved [17].

In 2017, the DLCG formulated an ambitious goal to double survival from lung cancer before 2030 [18] and it is widely recognised that the DLCR plays a crucial part in achieving this goal.

\section{The National Lung Cancer Audit (UK)}

In 1999, a multidisciplinary "intercollegiate" lung cancer group published: "Lung Cancer: a Core Dataset" [19]. From the outset, the aim was to achieve as near to total population coverage as possible; in order to make achieving this more likely, the size of the dataset was limited. It has evolved over the years [20], but the number of fields requiring completion for any one patient is usually less than 50 .

In 2004 the English Government, through the National Clinical and Patient Outcomes Programme, which funds over 30 national clinical audits in England, began to support the central functions of a national lung cancer audit (NLCA) programme. Wales joined the programme in 2006, and collated data from Scotland and Northern Ireland have been included in reports whenever possible.

The principles of the NLCA and findings were regularly presented at regional and national multi-professional clinical meetings to encourage clinical engagement, which was initially limited. However, despite non-mandatory participation, the proportion of patients captured by the audit rose from $40 \%$ in 2005 to $100 \%$ in 2009 and has remained at that level since. In 2009 participation was mandated by formal contract between the Department of Health and provider hospitals. 
A bespoke database was developed (Lung Cancer Data (LUCADA)) in one of the central computing systems of the National Health Service (NHS), allowing direct, secure entry of individual patient data or compiled grouped data on multiple patients as .csv or .xml formatted files. This system also allows each hospital to see its own grouped data at any time with comparative, anonymised data from other hospitals.

MDTs were already well established [21] and these teams were used as the focus for data collection, with some teams appointing data coordinators or building the work into the roles of MDT coordinators or even LCNSs. Each local hospital developed or purchased its own software for data collection, though by the late 2000 s $>80 \%$ were using one of two systems. Data completeness improved rapidly, e.g. completeness of performance status and stage data fields reached $>80 \%$ by 2009 [22] and have exceeded $90 \%$ since [23].

The first annual report of the NLCA was published and made available to the general public in 2006 [24]. The hospitals were identified along with their activity, data completeness and outcomes. This led to a great deal of press activity and complaints from hospitals that their data were not accurate, but this served as a vital driver behind the rapid improvements in participation and data completeness that followed. Reports and anonymised spreadsheets of data are now available to the public via the Royal College of Physicians' website [25].

Data quality and completeness are major issues for any large-scale population-based audit. Data on comorbidity proved to be difficult to collect, being both incomplete and inconsistent. As with the DLCR, the Charlson index is used, derived from inpatient diagnostic codes. Until recently, detailed data on combination therapies and second and subsequent lines of treatment have been limited; this is now collected through two other databases, one for radiotherapy and one for systemic therapy. Palliative care, primary care and patient-reported outcome measures have so far not been routinely linked to the NLCA.

The NLCA has changed the culture of the thoracic oncology community in the UK, raising awareness of local and regional activity, patterns of care, and outcomes of patients with lung cancer and mesothelioma. Surgical resection rates have doubled since the audit began and less dramatic improvements have been seen in a wide range of other indicators of high-quality care [25]. The 1- and 5-year survival rates have increased in recent years [26] and appear to parallel the improvements in treatment rates. A large number of peer-reviewed publications have emerged using the NLCA data and these have been influential in recommendations for the commissioning of services. In 2014 the NLCA team at the Royal College of Physicians began working directly with the National Cancer Registration and Analysis Service (NCRAS) in Public Health England and to a large extent now use data collected in the national Cancer Outcomes and Services Dataset (COSD) as the basis of their analyses and reports.

\section{Patient perspectives on the development of a pan-European lung cancer dataset}

The ELF lung cancer PAG was asked specific questions about the development of a pan-European dataset and the views outlined below are from five individuals with experience of lung cancer from the Czech Republic, Italy and the UK.

\section{Value of a pan-European dataset}

PAG members were in agreement that the implementation of a lung cancer dataset across Europe would be particularly useful in:

- developing and monitoring diagnostic standards;

- developing and monitoring standards of care in lung cancer;

- assisting evidence-based analysis of data across countries; and

- establishing what treatments work and for whom.

Patient access to data would be of interest and value to patients as a way to understand more about their condition and what could be viewed as usual or unusual in comparison with others. This would give individuals a useful comparator to discuss their condition with clinicians. In light of this, patient access to the data should be considered as part of any dataset development.

\section{Gathering data}

It was noted that patients could provide valuable input in defining the relevant importance of different quality of life (QoL) data and the considerations to be aware of when collecting these data. Patients felt it was important for QoL data to be collected verbally, directly from patients, to ensure consistency, and to identify patterns across the pathway which could then lead to the identification of relevant support where appropriate. A crucial factor for the successful gathering of information from the patient is the level of trust that exists between clinician and patient. The task force identified the QoL questionnaire from the European Organization for Research and Treatment of Cancer (EORTC QLQ-C30) as a possible resource 
because this is a standardised tool in current use [27]. The PAG members thought that some of the questions were relevant, but that a subset of these questions might be more effective.

PAG members suggested that there could be a beneficial role for caregivers, nurses and hospice staff in helping to gather QoL information and assisting patients, especially at times of high stress and anxiety. They identified these times as often being at the point of diagnosis; when patients may not have much energy, e.g. during chemotherapy; or when receiving palliative care. This will vary with each individual and further discussions would be beneficial to ensure data are both sensitively and effectively gathered. Patient-reported outcomes have demonstrated positive impact on treatment outcomes and their use is expected to increase in the future [28]. Specific recommendations on patient-reported outcomes are not dealt with in this recommendation.

The PAG thought QoL data collection would be most valuable at diagnosis, post primary treatment ( 3 months) and at the end of primary treatment ( 6 months). Several PAG members felt that it would be helpful to gather data after 12 months. It was also suggested that collecting QoL from patients at the end of a 5-year recurrence-free follow-up could be valuable in sharing hope among patients.

PAG members recommended that the gathering of comorbidity data should be patient led and clinician reported. These data should emerge from discussion and agreement between the clinician and patient. This would have the additional advantage of patients being better informed about potential comorbidities and provide opportunities for pre-agreement with their clinician about what to do should symptoms appear, potentially leading to lower patient anxiety in the long term.

\section{Implementation topics of importance to patients}

Implementation topics identified as important to patients included informed patient consent, data protection and data security, data use and patient knowledge of how it is used, and information about clinical trial involvement. Providing personalised data summaries with pan-European comparisons would also be a valued option.

ELF would recommend that patient representatives are fully involved in future discussions about dataset development to ensure that all patient issues have been considered and any potential challenges addressed before any future roll-out across Europe.

\section{Recommendations for a pan-European dataset for lung cancer registration}

The proposed pan-European dataset for lung cancer registration can be divided into four sections, with data items relating to basic patient features, tumour details, extended patient features and details of the lung cancer pathway and process (tables 1-4; these tables are available as a separate download as supplement 2). The tables include data items that should be mandatory in the minimum dataset (marked in black in supplement 2) as well those which are desirable (marked in blue in supplement 2). Data items in the minimum dataset were felt to be essential for the basic epidemiology required to evaluate key clinical outcome measures, and are already collected in a majority of European countries [11]. The minimum dataset for lung cancer (including tracheal cancer) is for all patients with an International Classification of Disease version 10 code of c33 or c34.

\section{Basic patient features}

Table 1 illustrates data items for basic patient features. A record of ethnicity is important for several reasons. There is evidence of significant variations in the prevalence of somatic mutations in adenocarcinoma of the lung based on ethnicity $[29,30]$. There is also evidence of variation in the route to accessing healthcare services based on patient ethnicity [31-33]. However, it is difficult to find one coding system for ethnicity that would capture the needs of every country in Europe. The ICHOM dataset definition [12] states that individual countries should determine the definition, and therefore this data item is not suitable for cross-country comparison. The task force therefore concluded that it was not possible to propose one list of ethnicity codes that would be relevant for every country in Europe (an example of a coding system is shown in supplement 1.3). The educational level of an individual was chosen as a surrogate for socioeconomic status. Some countries have well-established linkage between registries or independent lung cancer audit programmes and census data which allow them to stratify an individual's socioeconomic status. However, these are in the minority, and although socioeconomic status is a very important indicator of access to healthcare generally, as well as key clinical outcomes in thoracic oncology [34-36], a compromise was agreed. The task force adopted a simple outline of educational level achieved based on ICHOM (primary, secondary or tertiary) [12]. There is wide variation in the level of educational status achieved in different countries, and it is not an ideal surrogate for socioeconomic status, but despite this limitation it was thought that educational level would be a data item that could be captured.

Five data items relate to the diagnosis of lung cancer, i.e. how it was made, with the inclusion of pertinent dates; these will be powerful points of reference when interpreting the lung cancer pathway and processes 
TABLE 1 Basic patient features

\begin{tabular}{|c|c|c|}
\hline Data item & Definition & Detailed definition \\
\hline Date of birth & $\mathrm{dd} / \mathrm{mm} /$ yyyy & \\
\hline Sex & Male or female & $\begin{array}{l}1=\text { male } \\
2=\text { female } \\
999=\text { undisclosed/unknown }\end{array}$ \\
\hline Country of registration & ISO-3166 & Two-letter code \\
\hline Date of referral & $d d / m m / y y y y$ & $\begin{array}{l}\text { Date on which referral made with respect to potential lung cancer. This could include } \\
\text { self-referral, primary to secondary care, within secondary care. } \\
\text { Option for missing/unknown. }\end{array}$ \\
\hline \multirow[t]{4}{*}{ Basis of diagnosis } & Numerical code (ICHOM) & $\begin{array}{l}1=\text { clinical } \\
2=\text { histology } \\
3=\text { cytology } \\
999=\text { unknown }\end{array}$ \\
\hline & Clinical & $\begin{array}{l}\text { Diagnosis made before death with or without diagnostic techniques le.g. chest } \\
\text { radiography, endoscopy, imaging, ultrasound, exploratory surgeryl but without a } \\
\text { tissue diagnosis. }\end{array}$ \\
\hline & Histology & $\begin{array}{l}\text { Histological examination of tissue from the primary tumour or metastasis, including all } \\
\text { cutting and bone marrow biopsies. Also includes autopsy specimens. }\end{array}$ \\
\hline & Cytology & $\begin{array}{l}\text { Examination of cells whether from a primary or secondary site, including fluids } \\
\text { aspirated using endoscopes or needles. Also including microscopic examination of } \\
\text { peripheral blood films and trephine bone marrow aspirates. }\end{array}$ \\
\hline
\end{tabular}

Data items in roman are mandatory within the proposed minimum dataset; data items in italics are desirable within the dataset. dd/mm/yyyy: date, month, year; ICHOM: International Consortium for Health Outcome Measures; IARC: International Agency for Research on Cancer.

within each country or between countries. Delays in referral to a lung cancer specialist have been proposed as a reason for differences in outcomes, so the date of referral to a lung cancer specialist is included. The route to a lung cancer specialist varies across Europe, and it often does not involve a primary care physician [10]. There is a hierarchical basis to the date of diagnosis, which is taken from the ENCR minimum 
dataset for cancer registries [9]. The date of the final pathology report reflects the need to identify delays in obtaining a complete pathological diagnosis that are consequent upon increasingly complex processing. The mode of presentation is an essential data item because it is known to influence prognosis.

The basis of diagnosis (clinical/radiological or pathological) is crucial because of the association with prognosis: a more precise identification of the denominator for the whole cohort allows international comparisons to reduce selection bias. Comparisons must use the same denominator because cohorts that only include patients with pathological confirmation do not include those patients with an often worse prognosis, who are diagnosed purely on the basis of a high level of clinical suspicion; such patients are often too unwell or too frail to undergo further tests. There is evidence that the likelihood of obtaining pathological confirmation in individuals believed to have lung cancer is affected by several factors. These include age [37], socioeconomic status [38] and performance status (PS) [39]. Equally, factors relating to the lung cancer service could account for variation in pathological confirmation rates, and hence the recommendation for agreed standards among lung cancer services in Europe (see "Part 2. Manual of standards for lung cancer services in Europe"). Internationally there is no agreed pathological confirmation rate, but the NLCA of England found that higher pathological confirmation rates were most strongly associated with survival in patients with stage I/II disease who had a PS of 0-1 [40]. Thus, a stratified approach to pathological confirmation based on clinical features was suggested, rather than a single benchmark figure for pathological confirmation rate. The basis of diagnosis is the same as that defined by ICHOM [12].

\section{Tumour details}

Data that specify details of the tumour (table 2) are essential for international comparisons because of the strong influence on prognosis, type of treatment offered and prediction of treatment response. The pathological subtype is vital, and we know that different countries within Europe use different systems. The majority use the International Classification of Diseases for Oncology, 3rd edition, which incorporates all subtypes according to the current 2015 World Health Organization classification of lung tumors [41], including the new lung adenocarcinoma classification originally proposed by the International Association for the Study of Lung Cancer (IASLC), American Thoracic Society and ERS [42]. However, Denmark uses Systematized Nomenclature of Medicine (SNOMED). The task force recommends that data are entered into the system using whichever classification is standard practice within each country. Retrieval of specific pathological subtypes could then be reconstructed with automated algorithms. For those countries without a specific pathological classification system, we have created a small but clinically relevant list of pathological subtypes. The field of molecular analysis is expected to expand in the future and so the data collection system needs to be able to include new definitions as clinical practice changes. These changes could be incorporated during a revision programme every 2 years, in order to balance clinical development with practical utility.

Stage of disease at diagnosis is compliant with the IASLC staging system [43]. The basis of the stage reflects access to certain procedures as well as national guidelines for diagnosing lung cancer, so there are data fields to record which investigations have been performed prior to the formation of a "final pretreatment clinical stage". The version of the staging system (7th or 8th edition) is selected first, and then the individual T, N and $\mathrm{M}$ stage is entered. Further details about tumour size and the number and location of nodes and metastases then follow. Sub-classification of the extent of N2 disease is included as part of the desirable dataset, which could then be used to categorise the patient cohort based on either the Robinson classification [44] or the IASLC staging project (assuming N1 disease is also sub-classified; table 2) [45]. This level of detail from a pan-European cohort of individuals with lung cancer will allow for a comprehensive and very detailed analysis of the prognostic value of the current IASLC staging system.

\section{Extended patient features}

Table 3 captures the extended patient features. The main data item in this section is the PS of the individual at the time of diagnosis with lung cancer. The Eastern Cooperative Oncology Group (ECOG) system [46] (also known as the World Health Organization PS) is the most widely used method for recording this feature, although there is evidence that PS is only routinely collected in less than a third of European countries [11]. It is paramount that collecting this patient feature becomes routine in all registries or audit programmes given the important role PS plays in predicting outcome [39, 47-50].

The subsequent data items would allow a detailed evaluation of the clinical outcomes from lung cancer within and between countries. The majority of European countries do not collect many of these items, and it would take significant investment and political support to achieve this. Assessing comorbidities is a fundamental part of patient evaluation prior to making a treatment plan, and there is good evidence for the influence of comorbidity on outcome [51-54]. The Charlson index was developed in the late 1970s and validated on a cohort of patients with breast cancer [55]. It has subsequently been used in numerous 


\section{TABLE 2 Tumour details}

Data item

Histology
Definition

System used

Was this performed?

Numerical code

EGFR mutation

(ICHOM)

Numerical code

If activating mutation found, on which exon?

Numerical code

EGFR mutation T790M

Numerical code

ALK translocation

(ICHOM)

Numerical code

Ros 1

Numerical code

BRAF

Numerical code

$P D-L 1$ status

Numerical code

PD-L1 per cent expression Numerical code
Detailed definition

ICD-0-3 (covers the entire 2015 WHO Classification of Tumours of the Lung, Pleura, Thymus and Heart)

SNOMED

Based on which system is used, a list of possible options will appear, and the correct histology field can be ticked.

-down menu appears with a limited list:

$1=$ small cell carcinoma

$2=$ NSCLC NOS

$3=$ squamous cell carcinoma

$4=$ adenocarcinoma

$5=$ large cell neuroendocrine carcinoma

$6=$ carcinoid-typical

$7=$ carcinoid-atypical

$8=$ adenocarcinoma in situ

$9=$ spindle/pleiomorphic/giant cell NSCLC

$10=$ other (free text box appears)

999=unknown

$0=$ no

$1=$ yes

999=don't know

Indicate presence of EGFR activating mutation

$0=$ no

$1=$ yes

$2=$ failed analysis

999=don't know

$0=$ not relevant

$1=$ exon 18

$2=$ exon 19

$3=$ exon 21

999=don't know

Indicate presence of EGFR mutation of resistance

$0=$ no

$1=$ yes

2=failed analysis

999=don't know

Indicate presence of ALK translocation

$0=$ no

$1=$ yes

2=failed analysis

999=don't know

Indicate presence of Ros1 translocation

$0=$ no

$1=$ yes

2=failed analysis

999=don't know

Indicate presence of BRAF mutation

$0=$ no

$1=$ yes

2=failed analysis

999=don't know

Indicate PD-L1 status

$0=$ not expressed

$1=$ some expression

$2=$ failed analysis

999=don't know

$0=$ not applicable (i.e. 0 above)

$1=<1$

$2=1-9.9 \%$

$3=10-49 \%$

$4=>50 \%$ 


\section{TABLE 2 Continued}

Data item

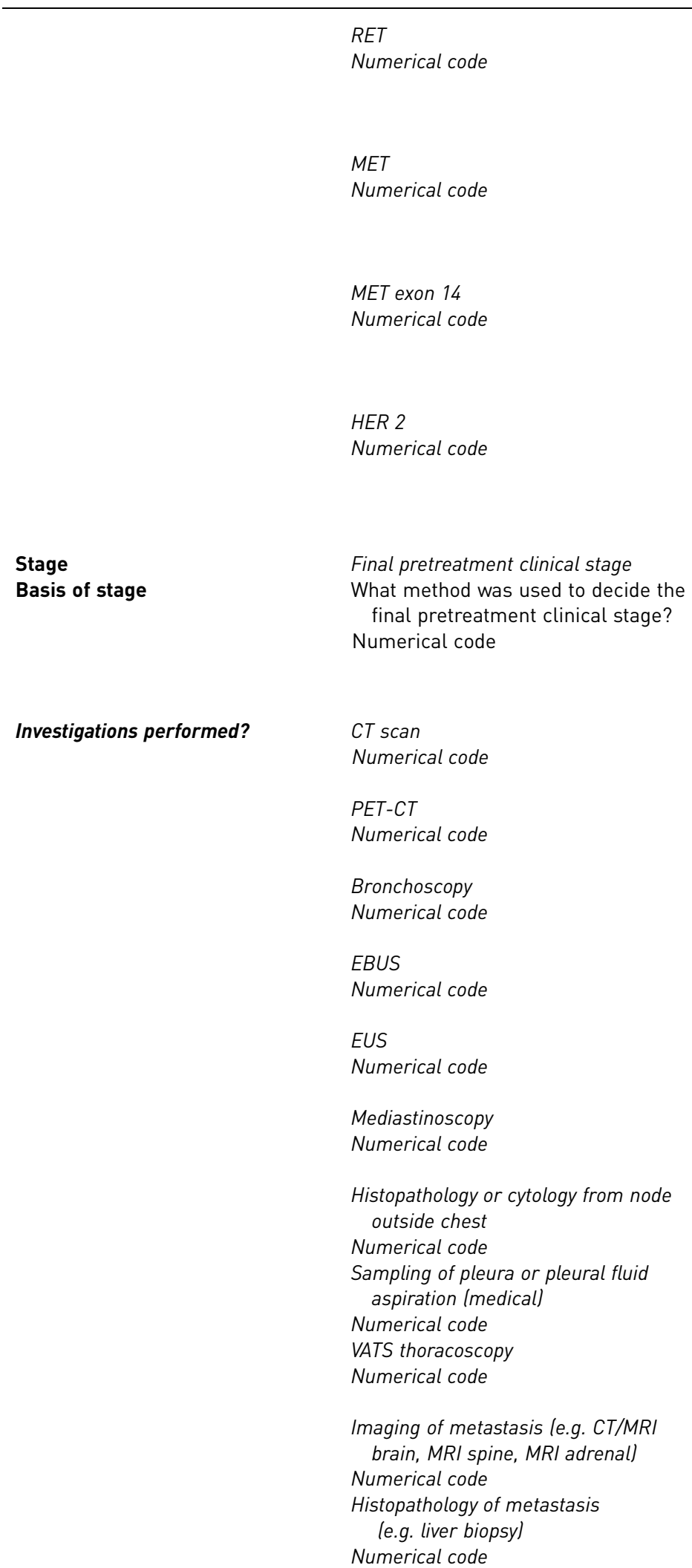

\section{Detailed definition}

Indicate presence of RET translocation

$0=$ no

$1=$ yes

2=failed analysis

999=don't know

Indicate presence of MET amplification

$0=$ no

$1=$ yes

2=failed analysis

999=don't know

Indicate presence of MET mutation exon 14

$0=$ no

$1=$ yes

2=failed analysis

999=don't know

Indicate presence of HER2 mutation

$0=$ no

$1=y e s$

$2=$ failed analysis

999=don't know

$0=$ imaging only

$1=$ imaging AND non-surgical pathology samples"

$2=$ imaging and surgical biopsies (mediastinoscopy, VATS procedurel

999=don't know

$0=$ no

$1=$ yes

999=don't know

$0=$ no

$1=$ yes

999=don't know

$0=$ no

$1=$ yes

999=don't know

$0=n o$

$1=y e s$

999=don't know

$0=$ no

$1=y e s$

999=don't know

$0=$ no

$1=y e s$

999=don't know

$0=$ no

$1=$ yes

999=don't know

$0=n o$

$1=$ yes

999=don't know

$0=$ no

$1=$ yes

999=don't know

$0=$ no

$1=y e s$

999=don't know

$0=$ no

$1=y e s$

999=don't know 
TABLE 2 Continued

Data item

\begin{tabular}{l}
\hline \\
Tumour size \\
Staging system
\end{tabular}

Tumour stage

Nodal stage

Extent of N1 disease

Extent of N2 disease

Metastasis stage

Number of metastatic lesions

Site of metastases
Definition

Exploratory open thoracic surgery

Numerical code

Numerical value

Which staging system has been used?

Mixed value

Mixed value

Numerical code

Numerical code

Mixed value

Numerical value

Liver

Numerical code

Brain

Numerical code

Adrenal

Numerical code

Bone

Numerical code

Other
Detailed definition

$1=$ yes

999=don't know

The longest single direction size in $\mathrm{cm}$ to one decimal point (e.g. 3.2)

IASLC 7th or 8th edition

Based on this answer; drop-down menu appears for T, N and $M$ stage.

IASLC 7th edition; 1 a through to 4

IASLC 8th edition; $1 \mathrm{mi}$ through to 4

999=unknown $/ X$

IASLC 7th or 8th edition; 0 through to 3

999=unknown

$0=$ not applicable

$1=$ single station $\mathrm{N} 1$ disease

2=multi-station N1 disease

$0=$ not applicable

$1=$ microscopic N2 node found at final pathological (post-operative) specimen

2=single station N2 node without N1 disease ('skip' lesion)

$3=$ single station $N 2$ node with $N 1$ involvement

4=multi-station N2 disease

$5=$ bulky or fixed multi-station N2 disease

IASLC 7th edition: 0 through to $1 \mathrm{~b}$

IASLC 8th edition: 0 through to $1 \mathrm{c}$

999=unknown/X

$0=$ no metastatic spread (i.e. M0 above)

1, 2, 3 onwards

999=don't know

$0=$ no

$1=y e s$

If yes, specify number of metastatic lesions 1, 2, 3 onwards 999=don't know

$0=$ no

$1=y e s$

If yes, number of metastatic lesions 1, 2, 3 onwards

999=don't know

$0=$ no

$1=y e s$

If yes, specify number of metastatic lesions 1, 2, 3 onwards

999=don't know

$0=$ no

$1=y e s$

If yes, specify number of metastatic lesions 1, 2, 3 onwards 999=don't know

Free text box to confirm site of spread

Data items in roman are mandatory within the proposed minimum dataset; data items in italics are desirable within the dataset. ICD-0-3: International Classification of Diseases - Oncology, 3rd edition; WHO: World Health Organization; SNOMED: Systematized Nomenclature of Medicine; NSCLC NOS: non-small cell lung cancer not otherwise specified; VATS: video-assisted thoracic surgery; EBUS: endobronchial ultrasound; EUS: endoscopic ultrasound; CT: computed tomography; PET: positron emission tomography; MRI: magnetic resonance imaging; IASLC: International Association for the Study of Lung Cancer; T: tumour; N: node; M: metastasis. \#: annual updates expected as molecular medicine develops; ๆ : definition of non-surgical samples: EBUS, EUS, percutaneous lung or pleural biopsy, pleural aspiration, bronchoscopy.

studies, but it has limited functionality given the complexity of the score, the lack of clarity regarding severity of comorbid disease and the out-of-date weighting given to HIV/AIDS. The Adult Comorbidity Evaluation-27 (ACE-27) score is an alternative model used by some to quantify comorbid disease [56], and some countries record specific comorbid diseases, but the list is variable [11]. Therefore, the ICHOM 
TABLE 3 Extended patient features

Data item Definition

Performance status (final pretreatment)

Smoking status

Smoking pack-years

Comorbidity at baseline from medical consultation with patient

Weight

Height

Lung function (at baseline)

Quality of life

At diagnosis

At end of first-line treatment

At 6 months post-diagnosis
ECOG (WHO)

Numerical code

Numerical code (ICHOM)

Numerical value

ICHOM-modified Self-administered Comorbidity Questionnaire [57]

Drop-down menu; multiple options possible

Numerical value
Numerical value
Numerical value (ICHOM)
Numerical value (ICHOM)
Numerical value
Numerical value

EORTC QLQ-C30

EORTC QLQ-C30

EORTC QLQ-C30

\section{Detailed definition}

$0=$ Able to carry out all normal activity without restriction.

$1=$ Restricted in physically strenuous activity, but able to walk and do light work.

2=Able to walk and capable of all self-care, but unable to carry out any work. Up and about more than $50 \%$ of waking hours.

$3=$ Capable of only limited self-care, confined to bed or chair more than $50 \%$ of waking hours.

$4=$ Completely disabled. Cannot carry on any self-care. Totally confined to bed or chair.

999=Unknown/not recorded

$1=$ never smoker $(<100$ cigarettes ever)

$2=e x-s m o k e r$ (stopped at least 1 year before inclusion, i.e. diagnosis)

$3=$ current smoker

999=don't know

The number of pack years smoked, regardless of ex or current smoker status (e.g. 20, 40)

999=don't know

Have you been told by a doctor that you have any of the following:

$0=I$ have no other diseases

$1=$ heart disease (e.g. angina, heart attack or heart failure)

2=high blood pressure

$3=$ leg pain when walking due to poor circulation

$4=$ lung disease (e.g. asthma, chronic bronchitis, COPD or emphysema)

$5=$ diabetes

$6=k i d n e y$ disease

$7=$ liver disease

$8=$ problems caused by stroke

$9=$ disease of the nervous system (e.g. Parkinson disease, multiple sclerosis)

$10=$ other cancer (within the last 5 years)

$11=$ depression

$12=$ arthritis

In $\mathrm{kg}$

999=don't know

$\ln m$

999=don't know

Observed FEV1 in L (e.g. 1.35)

999=don't know

FEV1 \% pred (e.g. 56 would represent $56 \%$ predicted)

999=don't know

Observed FVC in L (e.g. 2.3)

999=don't know

Kco \% pred (e.g. 85 would represent $85 \%$ predicted)

999=don't know

Score (maximum value 126)

Score (maximum value 126)

Score (maximum value 126)

Data items in roman are mandatory within the proposed minimum dataset; data items in italics are desirable within the dataset. ECOG: Eastern Cooperative Oncology Group; WHO: World Heath Organization; ICHOM: International Consortium for Health Outcome Measures; COPD: chronic obstructive pulmonary disease; FEV1: forced expiratory volume in $1 \mathrm{~s}$; FVC: forced vital capacity; Kco: transfer coefficient of the lung for carbon monoxide; EORTC QLQ: European Organization for Research and Treatment of Cancer Quality of Life Questionnaire.

list of comorbid diseases (based on SANGHA et al. [57]) is recommended, but should be derived from the medical notes after consultation between the clinician and the patient. It is hoped this will ensure accurate recording of all known comorbidities. The EORTC QLQ-C30 patient-completed questionnaire is recommended for QoL [27]. This is based on the fact it is a validated research tool [58], although our 
TABLE 4 Lung cancer outcomes

Data item

Definition

Detailed definition

Contact made with LCNS

Treatment intent

Ireflects the intent of the treating physician or MDT)

First-line treatment given to primary tumour

First-line treatment not given or change in treatment plan

Date of first-line treatment

\author{
Type of operation \\ Additional question only if \\ option 1 above
}

Curative

Non-curative

No active treatment

Numerical code

\author{
Numerical code \\ Numerical code
}

Numerical code

$\mathrm{dd} / \mathrm{mm} /$ yyyy

Numerical code

Staging system used Pathological stage
$0=$ no

$1=$ yes

999=don't know

$1=$ curative intent

$2=$ non-curative intent

$3=$ no active treatment

999=don't know

This is single or multimodality treatment which is hoped will remove the threat of lung cancer to the patient's life expectancy.

This is single or multimodality treatment which is expected to gain local control, or limit the progression of the disease, but is unlikely to remove the threat of lung cancer to the patient's life expectancy.

For those patients who decline, or are too frail for, radiotherapy or chemotherapy and receive medication for symptom control or a watch and wait policy.

Choose one option only from the list below:

$1=$ surgery alone

2=hyperfractionated radiotherapy

$3=$ external beam radiotherapy (curative intent but not CHART)

$4=$ stereotactic radiotherapy

$5=$ radiofrequency/microwave ablation

$6=$ brachytherapy

$7=$ palliative radiotherapy to lung primary

$8=$ concurrent chemoradiotherapy

$9=$ sequential chemoradiotherapy

$10=$ induction radiotherapy (pre-surgery)

$11=$ induction chemotherapy (pre-surgery)

$12=$ palliative chemotherapy

13=targeted/biological therapy (TKI etc.)

$14=$ immunotherapy

$15=$ interventional bronchoscopy

$16=$ specialist palliative care

$17=$ other (free text)

999=don't know/not recorded

$0=$ not relevant

$1=$ patient declined first-line treatment offered

$2=$ patient deteriorated and no longer eligible for first-line treatment

$3=$ hospital unable to provide first-line treatment $4=0$ ther (free text)

Date of the start of first-line treatment, i.e. date of operation, first day of radiotherapy or chemotherapy regime, or appointment with specialist palliative care physician.

$0=$ incomplete resection (residual macroscopic disease evident) $1=$ segmentectomy

$2=$ wedge resection

$3=$ lobectomy

$4=$ bi-lobectomy

$5=$ sleeve lobectomy

$6=$ pneumonectomy

999=don't know

IASLC 7th or 8th edition

Based on version used can then have drop-down menu for pathological stage 


\section{TABLE 4 Continued}

\section{Data item}

Nature of radiotherapy

Additional question only if options 2, 3, 4, 7 or 10 chosen

\section{Nature of chemotherapy Additional question only if options 11 or 12 chosen}

\section{Additional supportive first-line treatment given?}

Type of additional supportive first-line treatment

\section{Definition}

Total dose given (Grey)

Number of fractions

Number of days or radiotherapy treatment

Numerical code

Numerical code

Numerical code

$d d / m m / y y y y$

Date of first radiotherapy session

Nature of radiotherapy (1-8 above)

\section{Date of palliative care}

Date of surgery

Date of pleural intervention

Type of pleural intervention

How is the patient followed up after first-line treatment?

\section{Date of completion of first-line treatment}

\section{Response to first-line treatment}

Date of relapse

How was relapse detected?
Total dose given (Grey)

Number of fractions

Number of days or radiotherapy treatment

$d d / m m / y y y y$

$d d / m m / y y y y$

$d d / m m / y y y y$

Numerical code

Numerical code. Pick single item from list.

Options are ranked in descending order. If multiple answers apply, pick the first answer in the list.

$d d / m m / y y y y$

Numerical code

$d d / m m / y y y y$

Numerical code

\section{Detailed definition}

Absolute number

Absolute number (e.g. 6)

Absolute number (e.g. 12)

$1=$ single agent chemotherapy

2=doublet platinum-based chemotherapy

$3=$ other (free text)

999=don't know

$0=$ no

$1=$ yes

If yes, then further question appears

$1=$ stereotactic radiotherapy to brain metastases

$2=$ radiotherapy for spinal cord compression

$3=$ prophylactic cranial irradiation

$4=$ whole brain radiotherapy

$5=$ radiotherapy for oligometastases

$6=S A B R$ for oligometastases

$7=$ radiotherapy for $\mathrm{SVCO}$

$8=$ radiotherapy to mediastinum

$9=$ specialist palliative care

$10=$ surgical resection of metastases

$11=$ pleural intervention (see below)

$12=$ other (free text)

Absolute number (e.g. 30)

Absolute number (e.g. 6)

Absolute number (e.g. 12)

Date of first appointment with specialist palliative care physician

\author{
$1=$ thoracocentesis \\ $2=$ chest drain \\ $3=$ pleurodesis \\ $4=$ indwelling chest drain
}

$1=$ regular outpatient visits with physician (member of MDT)

2=follow-up with LCNS

3=virtual follow-up after imaging

$4=$ telephone contact with patient

$5=$ referred back to primary care doctor

$0=$ no follow-up

999=don't know

\section{$0=$ complete remission \\ $1=$ partial response \\ $2=$ stable disease \\ $3=$ progression \\ 999=don't know}

$0=$ planned imaging

$1=$ symptoms

$2=$ incidental finding with unrelated problem

999=don't know 
TABLE 4 Continued

\section{Subsequent treatment to lung} primary
Numerical code
More than one treatment option can be chosen during the patient treatment programme (please confirm with dates below)

$1=$ surgery

2=chemotherapy and radiotherapy in addition to surgery (tri-modality treatment)

$3=$ hyperfractionated radiotherapy

$4=e x t e r n a l$ beam radiotherapy (curative intent but not $\mathrm{CHART}$ )

$5=$ stereotactic radiotherapy (3-8 fractions)

$6=$ radiofrequency/microwave ablation

$7=$ brachytherapy

$8=$ palliative radiotherapy to lung primary

$9=$ concurrent chemoradiotherapy

$10=$ sequential chemoradiotherapy

$11=$ palliative chemotherapy

12=targeted/biological therapy (TKI etc.)

13=immunotherapy

14=interventional bronchoscopy

$15=$ specialist palliative care

999=don't know/not recorded

\section{Date of surgery}

Date of first radiotherapy session

Nature of radiotherapy

Date of first chemotherapy dose

Date of last chemotherapy dose

Date of interventional bronchoscopy

Date of specialist palliative care

Clinical trial

Date of death $d d / m m / y y y y$

$\mathrm{dd} / \mathrm{mm} / \mathrm{yyyy}$

Total dose given (Grey)

Number of fractions given

Number of days of radiotherapy

treatment

$d d / m m / y y y y$

$d d / m m / y y y y$

$d d / m m / y y y y$

$d d / m m / y y y y$

Is the patient part of a clinical trial?

Numerical code
Absolute number (e.g. 30)

Absolute number (e.g. 6)

Absolute number (e.g. 12)
Date of first appointment with specialist palliative care physician

$0=$ no

$1=$ yes

999=don't know $\mathrm{dd} / \mathrm{mm} /$ yyyy

Data items in roman are mandatory within the proposed minimum dataset; data items in italics are desirable within the dataset. LCNS: lung cancer nurse specialist; MDT: multidisciplinary team; CHART: continuous hyperfractionated accelerated radiotherapy treatment; dd/mm/yyyy: date, month, year; IASLC: International Association for the Study of Lung Cancer; SABR: stereotactic ablative radiotherapy; SVCO: superior vena cava obstruction.

patient group felt only a subset of the questions were relevant. This questionnaire should be completed at diagnosis, after completion of first-line treatment and at 6 months post-diagnosis. This may be difficult to achieve but QoL for patients is a fundamental outcome measure, often neglected. Members of our PAG felt that ideally we would also collect QoL data at 12 months and after 5-year survival, where applicable. A revised QoL questionnaire is in development, which incorporates elements of the QLQ-C30 with specific reference to side effects from medical treatments including chemotherapy and targeted therapies [59].

\section{Lung cancer pathway/outcomes}

The final section of the European recommended minimum dataset relates to aspects of the lung cancer pathway, specifically the outcomes in terms of treatment and survival (table 4). Patients in some countries have identified how important contact with a LCNS is because they provide significant support to patients and their families throughout the lung cancer pathway. Although there is no accepted international definition for a LCNS, the task force suggests the following: a LCNS is one whose primary role is to meet individuals with lung cancer at diagnosis, sometimes before, and then to provide support to the patient and their family in terms of education, access to benefits, liaising with primary care physicians and 
emotional support. The role may include other duties, such as administering chemotherapy, although this does not on its own meet the essential elements of holistic care described above.

Treatment data items are shown in table 4 and provide a comprehensive list of treatment options and associated secondary questions, which would not apply to all cases. In order for meaningful analysis of lung cancer outcomes to take place, and the influence of treatment modalities on survival to be assessed, every effort must be made to capture all relevant information.

\section{Part 2. Manual of standards for lung cancer services in Europe}

Publications defining lung cancer service specification had variable content. Four broad areas were identified that distinguished them:

- geographic scope (international, national or regional setting);

- comprehensiveness of care (comprehensive cancer services, lung cancer-specific services and services that provide only selected diagnostic or treatment modalities);

- publishing body, such as national or international healthcare authorities or medical societies, insurance companies or other non-governmental bodies reimbursing costs of care, foundations, or a combination of these bodies; and

- the time point and up-to-dateness of publication.

No international initiatives could be identified which defined standards of care specifically for the entire lung cancer pathway, although there are two examples of relatively comprehensive cancer care service definitions on the European level. These are the European Society for Medical Oncology Designated Centres of Integrated Oncology and Palliative Care accreditation programme, initiated in 2003 [60], and the Organisation of European Cancer Institutes (OECI) Accreditation and Designation Programme, revised in 2015 [61]. Several international medical societies have published statement papers on standards for selected parts of the lung cancer pathway (supplement 1.2).

The US National Cancer Institute (NCI) established the first successful comprehensive cancer centre programme in 1971, supported by the National Cancer Act. There are now 69 NCI-designated (Comprehensive) Cancer Centers, all of which have a focus on basic, clinical and population-based research [62]. This has been reviewed in relation to developing centres in Europe to support, primarily, research [63].

The Bonnie J. Addario Lung Cancer Foundation has established its own foundation-based "Centre of Excellence Program", currently encompassing 17 community hospitals as well as 17 Addario Lung Cancer Medical Institute hospitals in the USA and three in Europe (Paris, France; Torino, Italy; and Barcelona, Spain) [64].

A number of other approaches have been taken to formalise the lung cancer pathway within European countries, and these are described in the paragraphs below.

UK

In 1995, the report by Calman and Hine, "A Policy Framework for Commissioning Cancer Services" [65], set the basic standards for cancer services in England and Wales including MDTs working as a core element of cancer services. Since then, the NHS has further developed and regularly updated standards of cancer centre-based care in the UK, and standards have been monitored through a national peer review process and the NLCA $[19,20,22]$. Furthermore, a national optimal clinical pathway for suspected and confirmed lung cancer: from referral to treatment" has been published [66]. In 2014, Cancer Research UK named the "Lung Cancer Centres of Excellence", jointly based in London and Manchester, whose aim is to develop and promote high-level lung cancer research [67].

\section{Denmark}

In Denmark, as mentioned above, the DLCG, through the DLCR and the national lung cancer guideline programme and in collaboration with national healthcare authorities, catalysed a process of continuous improvement of lung cancer care which has, among other things, instigated a re-organisation with centralisation of Danish lung cancer services [17]. Supplement 1.4 depicts the lung cancer service in the region of Southern Denmark.

\section{France}

France has a national task force against cancer that has developed three national "cancer plans" [68]. The first cancer plan, launched by President Chirac (2003-2007), set the basis of a national strategy for multidisciplinary management of cancer. It legalised the compulsory multidisciplinary discussion of each individual cancer patient. MDTs are organised according to organ or system; within thoracic oncology, 
pleural mesothelioma and thymic epithelial tumours fall within the remit of rare tumour boards (national), rather than the lung MDT. The MDT discussion must lead to a consensual personalised treatment plan, which is a written document given to the patient during a structured consultation, and a nurse coordinator is also present to offer psychological or social support if required. The plan is also sent to the patient's general practitioner and all corresponding doctors.

The first cancer plan also elaborated on the accreditation of units caring for patients with cancer, and in particular of surgical units. A surgical unit should host at least two surgeons, have access to an intensive care unit and an endoscopy suite, and have a frozen section analysis available on site. Minimum thresholds have been set per organ, which result in a minimal caseload of 20 major resections per surgeon (respectively 30 cases per unit, given some surgeons work on more than just cancer).

The Ministry of Health created a national institute of cancer (Institut National du Cancer (INCa)) in 2005, which coordinates research and treatment in oncology. INCa publishes an annual report and collaborates with 25 regional oncology networks, which coordinate screening and treatment at the regional level. INCa is also connected to the Higher Authority of Health (Haute Autorité de la Santé, HAS), which is in charge of editing guidelines and quality control. Finally, INCa has accredited and coordinates eight inter-groups for clinical research, including the French Intergroup of Thoracic Oncology (IFCT).

Two subsequent cancer plans have been launched by presidents Sarkozy (2009-2013) and Hollande (2014-2019). The third cancer plan is an ambitious document [69] that not only aims to improve treatment, but also to act before diagnosis (prevention, screening) and after treatment (follow-up, social re-integration).

\section{Germany}

In 2008, the German Cancer Society in collaboration with the German Respiratory Society and the German Society of Thoracic Surgery initiated a certification programme for lung cancer centres as part of the German National Cancer Plan. In September 2016 there were 44 certified lung cancer centres in Germany and two in Switzerland. The certification process comprises:

- an annual updated parameter manual with mandatory and recommended elements of structure, process and outcome data which are used for self-assessment and subsequent external validation;

- annual visits to the respective lung cancer service by trained external specialists;

- an extensive evaluation of the results by an independent institute; and

- a final evaluation $[70,71]$.

The German parameter manual contains 10 chapters covering mainly medical aspects of the lung cancer pathway. Multi-professional/disciplinary working is encouraged and there are specific mandatory standards for centres. These include diagnosing and treating $\geqslant 200$ new patients with pathologically confirmed lung cancer per year and $\geqslant 75$ anatomical lung cancer resections per year, and recording performance indicators such as a $\leqslant 5 \% 30$-day mortality after anatomical lung cancer resections, and $\geqslant 10 \%$ proportion of broncho-/angioplastic resections on all anatomical resections. Clinical lung cancer registration and follow-up data collection are mandatory in every certified lung cancer centre and their close linkage to the newly established clinical cancer registries of the 16 German Federal States is promoted [70, 71]. The process has seen improvements in multidisciplinary working.

Only 33\% of all new cases of lung cancer in 2016 were covered by certified lung cancer centres. The main obstacles for broader implementation are the mandatory thresholds for new cases and surgical resections $[70,71]$. Other medical societies in Germany have established independent certification programmes related to lung cancer care (i.e. the "Oncological Centres" of the German Society for Haematology and Medical Oncology and the "Thoracic Centres" of the German Society of Thoracic Surgery, the latter initiative appraising both benign and malignant disease) $[72,73]$.

\section{Overview of the development of the manual of standards for lung cancer services in Europe}

The task force group agreed on the following scope and core principles for developing the parameter manual of European standards for lung cancer services:

1) The primary target audience of the parameter manual is professionals involved in lung cancer care in Europe. The standards will also be important for lung cancer patients, their carers and other stakeholders in lung cancer care.

2) The main aim is to harmonise and improve standards of lung cancer care throughout Europe. Multidisciplinary teamwork and patient-centred care are central. 
3) The parameter manual is composed of two sections covering i) infrastructure and organisation of the lung cancer service; and ii) standards for lung cancer services at each stage of the lung cancer pathway.

4) Standards are divided into essential and advanced. "Essential standards" are defined as criteria which are mandatory for the lung cancer service to fulfil basic standards of effective care. "Advanced standards" are defined as those that go beyond that which is essential to provide higher-quality lung cancer care.

5) The underlying evidence base for the essential and advanced standards was graded into three levels: i) "Guideline": wherever possible, generally accepted clinical lung cancer guideline recommendations were used to conclude standards for the infrastructure or pathway for lung cancer services (i.e. the guideline recommendation "Lung cancer patients who are potentially suitable for treatment with curative intent should be offered PET-CT [positron emission tomography computed tomography] before treatment" led to the essential standard in this manual "The lung cancer service must provide or have access to PET-CT"; ii) "Literature review and assessment": these denoted that standards were based on an assessment of the available non-guideline literature; iii) "Good practice": in the absence of any guideline recommendations or other literature, task force members and patient representatives used their clinical experience to reach conclusions about what constitutes good clinical practice for certain standards.

6) It is acknowledged that differences in terminology can lead to differences in interpretation across Europe; a glossary for the terminology is provided in supplement 3.

The PAG has already formulated patient priorities in lung cancer care, which were published in an ELF report [74]. These patient priorities comprise proper patient involvement and the provision of relevant and understandable information needed for decision-making; quantitative and qualitative improvement of patient-professional contacts throughout the lung cancer pathway; better involvement of other professions, especially lung cancer nurses; supervision and psychological support for doctors and other professionals; specific communication training for professionals; and better linkage between lung cancer services.

\section{Recommendations for a pan-European manual of standards for lung cancer services Organisation of the lung cancer service}

The manual of standards for a lung cancer service in Europe is provided as supplement 3. This first section addresses the relevant organisational aspects of the lung cancer service as a whole. Although a multidisciplinary network environment is an essential requirement, it was agreed that the specific membership should be determined according to the local and/or national setting. Advanced standards have been formulated to encourage lung cancer services that have a full range of diagnostic and/or treatment facilities to offer these to partner organisations. It is important to note that there is no one infrastructure that every service should adopt. Every aspect of the lung cancer pathway should be available to the individual patient, but the delivery of this may vary at the local level. A real-life example of a multi-site lung cancer service from Denmark is included in supplement 1.4.

The PAG also elaborated on the standards for patient- and carer-centred care. The evidence base for this is limited, although not strictly necessary when a patient expert group has commented and when there are several national lung cancer guidelines recommending shared decision-making on the basis of information that is easy to access and understand [75].

The task force identified further "essential standards" in a lung cancer service which relate to:

- adherence to evidence-based care, with use of regularly updated guidelines;

- access to specialised care;

- timeliness of care;

- documentation, accessibility and provision of patient and carer-related information;

- communication and environment for communication;

- education for healthcare professionals, patients and carers (e.g. the Thoracic Oncology HERMES syllabus and curriculum [76-80]);

- clinical cancer registration;

- quality assurance, quality improvement and risk management; and

- collaboration with external healthcare professionals and other external stakeholders by the lung cancer service.

The utilisation of the proposed pan-European dataset for lung cancer registration is recommended as an advanced standard. Advanced collaborative measures have been proposed by the task force group to facilitate local, regional, national and international networking. 


\section{Lung cancer pathway}

The second section of the manual encompasses the entire lung cancer pathway within the lung cancer service, from diagnosis through treatment, follow-up, relapse and end of life or survivorship (supplement 3). The underlying international and national guidelines which provide recommendations related to most of the essential and advanced standards within this section are listed in supplement 1.2.

Cross-pathway care is included in this section. This is often important to ensure that the patient's experience is maximised when care is needed from services outside the lung cancer pathway; these may include emergency care, intensive care and services for specific symptom management. Palliative care is included here but it is noted that this should be provided throughout the entire pathway (figure 1) [81].

Pre-existing statement papers and recommendations issued by other international medical societies have been reviewed and incorporated into the manual of standards where appropriate. These include imaging [82], fitness for diagnostics and radical therapy [83], thoracic surgery [84], radiotherapy [85-93] and palliative care [94]. Owing to limited evidence and heterogeneity among and within European countries, the task force group was unable to define standards for individual or institutional volumes of care and timeliness/waiting times.

\section{The future: implementation of harmonised standards in Europe}

The proposed pan-European lung cancer dataset and manual of standards for lung cancer services provides the opportunity to harmonise registration and quality of services in Europe. A previous ERS task force showed marked inequalities in lung cancer care among and within European countries [10], and importantly established a network of interested clinicians who are ready to be involved with the implementation of these standards. Thus, we have so far identified variation and reviewed guidelines, and this paper defines both a pan-European dataset and standards for lung cancer services.

Our proposed standards for lung cancer services and lung cancer registration comprise two essential parts of a lung cancer guideline cycle based on the model originally introduced by the European Commission in 2004 (figure 2) $[95,96]$. Given the surplus of existing lung cancer guidelines and, as a consequence, the substantial waste of human and financial resources, it is imperative that multiple uncoordinated initiatives on the international, national and regional level should be avoided. Therefore, the ERS will seek collaborations on a par with other leading European societies to define joint pan-European standards for lung cancer services and lung cancer registration based on this statement paper as well as multi-professional, patient-centred lung cancer guidelines. This would also save valuable resources on the national and regional level. Given the rapidly evolving field of lung cancer care, these standards will need to be revised on a regular basis to ensure their relevance and efficacy.

Dissemination and implementation of these standards is vital. Although there are some examples of service improvement initiated through involvement of individual members of the task force, it is now important to actively manage the process of improving services, care and outcomes throughout Europe. This may be done using methods of service improvement that have been used in individual countries using our established network. Peer review is one such established method. This allows individuals and teams to review each other's services, with reference to agreed standards [97]. In the European setting this process could really drive up standards of care. The peer review process will involve clinicians visiting and evaluating services that may be very different, with the opportunity to suggest some profoundly helpful changes and to learn from one another. Following a recent feasibility project benchmarking lung cancer services in Glasgow and Berlin, the ERS will endeavour to support peer review projects on a pan-European scale.

In summary, the task forces of the ERS Thoracic Oncology Assembly have so far provided important information about the variation in lung cancer care in a range of European countries with marked

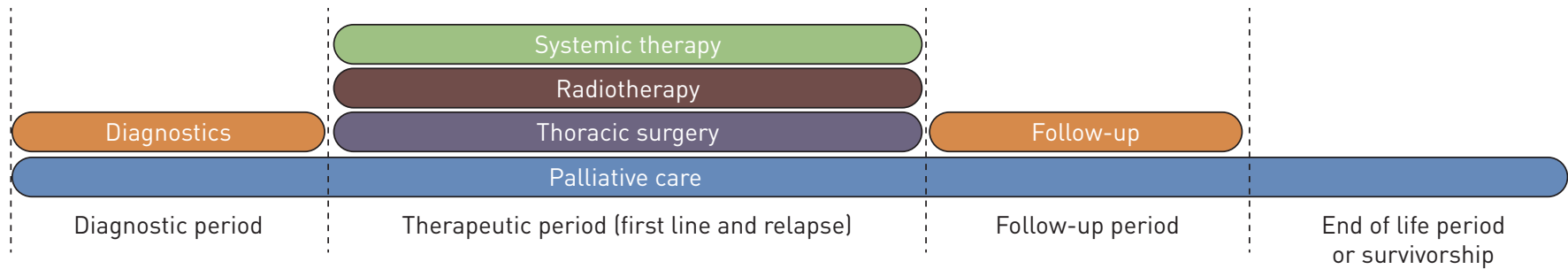

FIGURE 1 Novel integrated lung cancer care concept with diagnostics, systemic therapy, radiotherapy, surgery, palliative care and follow-up as equitable pillars of lung cancer care. Adapted from [81]. 


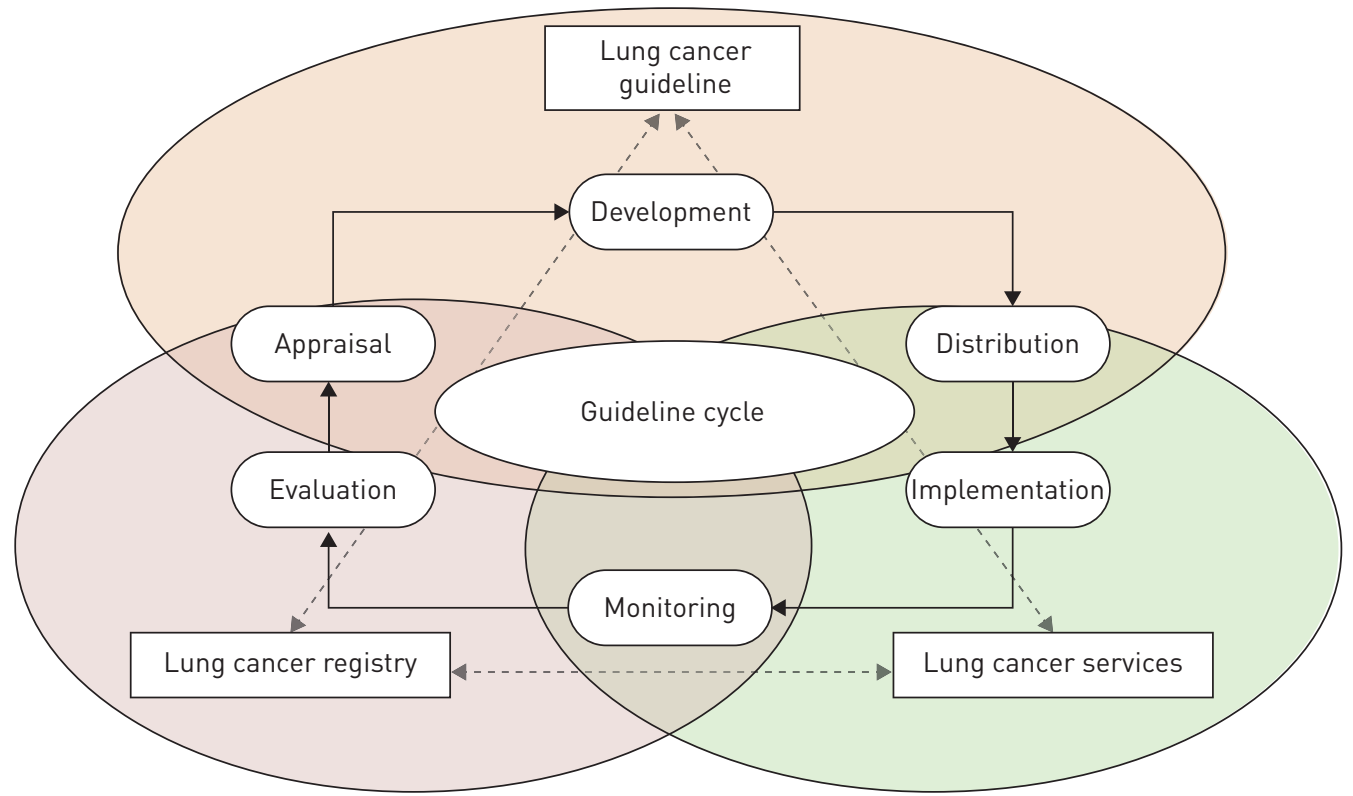

FIGURE 2 Lung cancer guideline cycle. Adapted from [96].

differences in social and political backgrounds. The next phase is to start the process of service improvement, while acknowledging the variable resources available in individual countries. It is envisaged that this current task force project will form the basis of a multinational, multi-society and patient-centred lung cancer care collaboration with the clear aim to improve and harmonise standards of lung cancer care for the benefit of patients, their carers and professionals alike.

Acknowledgements: The task force would like to thank members of the European Lung Foundation lung cancer patient advisory group who provided valuable feedback on both aspects of this project. Specifically, we would like to recognise the collaboration of Blanka Čepická (Czech Republic), Margaret Gould (UK), Vagn Jespersen (Denmark), Terry Kavanagh (UK), Ewelina Szmytke (Poland), Stefania Vallone (Italy), Dan Smyth (Ireland), Janette Rawlinson (UK) and Tom Simpson (UK).

Conflict of interest: A.L. Rich has nothing to disclose. D.R. Baldwin reports personal fees for lecturing from AstraZeneca, outside the submitted work. P. Beckett has nothing to disclose. T. Berghmans has nothing to disclose. J. Boyd is an employee of the European Lung Foundation. C. Faivre-Finn reports research funding and business travel support from Merck, AstraZeneca and Pfizer, outside the submitted work. F. Galateau Salle has nothing to disclose. F. Gamarra has nothing to disclose. B. Grigoriu has nothing to disclose. N-C.G. Hansen has nothing to disclose. G. Hardavella has nothing to disclose. E. Jakobsen has nothing to disclose. D. Jovanovic has nothing to disclose. A. Konsoulova has nothing to disclose. G. Massard has nothing to disclose. J. McPhelim reports personal fees from Roche, MSD, Pfizer, Lilly Oncology and Abbvie, outside the submitted work. A-P. Meert has nothing to disclose. R. Milroy has nothing to disclose. L. Mutti has nothing to disclose. M. Paesmans has nothing to disclose. M.D. Peake has nothing to disclose. P.M. Putora has nothing to disclose. D.K.M. de Ruysscher has nothing to disclose. J-P. Sculier has nothing to disclose. A. Scherpereel has nothing to disclose. D.R. Subotic has nothing to disclose. P. Van Schil has nothing to disclose. T.G. Blum has nothing to disclose.

\section{References}

1 Verdecchia A, Francisci S, Brenner H, et al. Recent cancer survival in Europe: a 2000-02 period analysis of EUROCARE-4 data. Lancet Oncol 2007; 8: 784-796.

2 Albreht T, McKee M, Alexe DM, et al. Making progress against cancer in Europe in 2008. Eur J Cancer 2008; 44: 1451-1456.

3 Oudkerk M, Devaraj A, Vliegenthart R, et al. European position statement on lung cancer screening. Lancet Oncol 2017; 18: e754-e766.

4 Berrino FSM, Verdecchia A, Capocaccia R, et al. Survival of Cancer Patients in Europe. The EUROCARE Study. Lyon, IARC Scientific Publications, 1995.

5 De Angelis R, Sant M, Coleman MP, et al. Cancer survival in Europe 1999-2007 by country and age: results of EUROCARE-5 - a population-based study. Lancet Oncol 2014; 15: 23-34.

6 Rossi S, Baili P, Capocaccia R, et al. The EUROCARE-5 study on cancer survival in Europe 1999-2007: database, quality checks and statistical analysis methods. Eur J Cancer 2015; 51: 2104-2119.

7 European Partnership for Action Against Cancer. http://ec.europa.eu/health/major_chronic_diseases/diseases/ cancer_en\#fragment1 Date last accessed: May 2017. 
8 Albreht T, Klasuwa R, Van den Bulcke M. European Guide on Quality Improvement in Comprehensive Cancer Control. Slovenia, Cancer Control Joint Action, 2017.

9 European Network of Cancer Registries. Recommendations for a Standard Dataset for the European Network of Cancer Registries 2005. Ispra, European Network of Cancer Registries, 2015.

10 Blum TG, Rich A, Baldwin D, et al. The European initiative for quality management in lung cancer care. Eur Respir J 2014; 43: 1254-1277.

11 Rich A BD, Alfageme I, Beckett P, et al. Achieving thoracic oncology data collection in Europe: a precursor study in 35 countries. BMC Cancer 2018; 18: 1144.

12 Mak KS, van Bommel AC, Stowell C, et al. Defining a standard set of patient-centred outcomes for lung cancer. Eur Respir J 2016; 48: 852-860.

13 Peake TS, Lowe D, Pearson M. Lung cancer: a national comparative audit. London, Royal College of Physicians, 1999.

14 The National Danish Health Authority. Referenceprogram Lungecancer Undersøgelse og behandling [Reference programme lung cancer: study and treatment]. 1998. www.lungecancer.dk/00164/ Date last updated: October 18, 2018.

15 Jakobsen E, Rasmussen TR. The Danish Lung Cancer Registry. Clin Epidemiol 2016; 8: 537-541.

16 Jakobsen E, Rasmussen TR, Green A. Mortality and survival of lung cancer in Denmark: results from the Danish Lung Cancer Group 2000-2012. Acta Oncol 2016; 55: Suppl. 2, 2-9.

17 Jakobsen E, Green A, Oesterlind K, et al. Nationwide quality improvement in lung cancer care: the role of the Danish Lung Cancer Group and Registry. J Thorac Oncol 2013; 8: 1238-1247.

18 Danish Lung Cancer Group. 2017. Visionsprojekt Lungekraeft Konferencerapport [Visions Project lung cancer conference report]. www.lungecancer.dk/documents/F1BFDA1D-EBFD-409A-A26A-15FF5385F00A.pdf.

19 Royal College of Physicians. Lung Cancer: a Core Dataset. 2nd Edn. London, Royal College of Physicians, 1999.

20 Beckett $\mathrm{P}$, Woolhouse I, Stanley R, et al. Exploring variations in lung cancer care across the UK - the "story so far" for the National Lung Cancer Audit. Clin Med (Lond) 2012; 12: 14-18.

21 Powell HA, Baldwin DR. Multidisciplinary team management in thoracic oncology: more than just a concept? Eur Respir J 2014; 43: 1776-1786.

22 The Healthcare Quality Improvement Partnership. National Lung Cancer Audit 2010. Leeds, NHS Health and Social Care Information Centre, 2010.

23 Royal College of Physicians. National Lung Cancer Audit annual report 2016. London, Royal College of Physicians, 2017.

24 NHS Health and Social Care Information Centre. National Lung Cancer Audit. Leeds, NHS Health and Social Care Information Centre, 2006.

25 Royal College of Physicians. The National Lung Cancer Audit. www.rcplondon.ac.uk/projects/ national-lung-cancer-audit Date last accessed: June 2018.

26 Walters S, Benitez-Majano S, Muller P, et al. Is England closing the international gap in cancer survival? $\mathrm{Br} \mathrm{J}$ Cancer 2015; 113: 848-860.

27 Bergman B, Aaronson NK, Ahmedzai S, et al. The EORTC QLQ-LC13: a modular supplement to the EORTC Core Quality of Life Questionnaire (QLQ-C30) for use in lung cancer clinical trials. EORTC Study Group on Quality of Life. Eur J Cancer 1994; 30A: 635-642.

28 Basch E, Iasonos A, Barz A, et al. Long-term toxicity monitoring via electronic patient-reported outcomes in patients receiving chemotherapy. J Clin Oncol 2007; 25: 5374-5380.

29 Midha A, Dearden S, McCormack R. EGFR mutation incidence in non-small-cell lung cancer of adenocarcinoma histology: a systematic review and global map by ethnicity (mutMapII). Am J Cancer Res 2015; 5: 2892-2911.

30 Dearden S, Stevens $\mathrm{J}, \mathrm{Wu} \mathrm{YL}$, et al. Mutation incidence and coincidence in non small-cell lung cancer: meta-analyses by ethnicity and histology (mutMap). Ann Oncol 2013; 24: 2371-2376.

31 Page BJ, Bowman RV, Yang IA, et al. A survey of lung cancer in rural and remote Aboriginal and Torres Strait Islander communities in Queensland: health views that impact on early diagnosis and treatment. Intern Med J 2016; 46: 171-176.

32 Gibberd A, Supramaniam R, Dillon A, et al. Lung cancer treatment and mortality for Aboriginal people in New South Wales, Australia: results from a population-based record linkage study and medical record audit. BMC Cancer 2016; 16: 289.

33 Department of Health. Cancer Reform Strategy: Equality Impact Assessment. London, Department of Health, 2007.

34 Rich AL, Tata LJ, Stanley RA, et al. Lung cancer in England: information from the National Lung Cancer Audit (LUCADA). Lung Cancer 2011; 72: 16-22.

35 Denton EJ, Hart D, Russell PA, et al. Lung cancer and socio-economic status: inextricably linked to place of residence. Intern Med J 2017; 47: 563-569.

36 Tannenbaum SL, Koru-Sengul T, Zhao W, et al. Survival disparities in non-small cell lung cancer by race, ethnicity, and socioeconomic status. Cancer J 2014; 20: 237-245.

37 Crawford SM, Atherton F. Lung cancer: histological aspects of diagnosis in England and the south east Netherlands. J Epidemiol Community Health 1994; 48: 420-421.

38 Crawford SM, Sauerzapf V, Haynes R, et al. Social and geographical factors affecting access to treatment of lung cancer. Br J Cancer 2009; 101: 897-901.

39 Maclay JD, Farley JM, McCowan C, et al. Obtaining tissue diagnosis in lung cancer patients with poor performance status and its influence on treatment and survival. Respir Med 2017; 124: 30-35.

40 Khakwani A, Rich AL, Tata LJ, et al. The pathological confirmation rate of lung cancer in England using the NLCA database. Lung Cancer 2013; 79: 125-131.

41 Travis WD, Brambilla E, Burke AP, et al. Introduction to The 2015 World Health Organization Classification of Tumors of the Lung, Pleura, Thymus, and Heart. J Thorac Oncol 2015; 10: 1240-1242.

42 Travis WD, Brambilla E, Noguchi M, et al. International Association for the Study of Lung Cancer/American Thoracic Society/European Respiratory Society international multidisciplinary classification of lung adenocarcinoma. J Thorac Oncol 2011; 6: 244-285.

43 Goldstraw P, Chansky K, Crowley J, et al. The IASLC Lung Cancer Staging Project: proposals for revision of the TNM stage groupings in the forthcoming (eighth) edition of the TNM classification for lung cancer. $J$ Thorac Oncol 2016; 11: 39-51. 
44 Robinson LA, Ruckdeschel JC, Wagner H Jr, et al. Treatment of non-small cell lung cancer-stage IIIA: ACCP evidence-based clinical practice guidelines (2nd edition). Chest 2007; 132: 3 Suppl., 243S-265S.

45 Asamura H, Chansky K, Crowley J, et al. The International Association for the Study of Lung Cancer Lung Cancer Staging Project: proposals for the revision of the N descriptors in the forthcoming 8th edition of the TNM classification for lung cancer. J Thorac Oncol 2015; 10: 1675-1684.

46 Oken MM, Creech RH, Tormey DC, et al. Toxicity and response criteria of the Eastern Cooperative Oncology Group. Am J Clin Oncol 1982; 5: 649-655.

47 Rich AL, Tata LJ, Free CM, et al. Inequalities in outcomes for non-small cell lung cancer: the influence of clinical characteristics and features of the local lung cancer service. Thorax 2011; 66: 1078-1084.

48 Rich AL, Tata LJ, Free CM, et al. How do patient and hospital features influence outcomes in small-cell lung cancer in England? Br J Cancer 2011; 105: 746-752.

49 Kawaguchi T, Takada M, Kubo A, et al. Performance status and smoking status are independent favorable prognostic factors for survival in non-small cell lung cancer: a comprehensive analysis of 26,957 patients with NSCLC. J Thorac Oncol 2010; 5: 620-630.

50 Reck M, Thatcher N, Smit EF, et al. Baseline quality of life and performance status as prognostic factors in patients with extensive-stage disease small cell lung cancer treated with pemetrexed plus carboplatin versus etoposide plus carboplatin. Lung Cancer 2012; 78: 276-281.

51 Edwards BK, Noone AM, Mariotto AB, et al. Annual Report to the Nation on the status of cancer, 1975-2010, featuring prevalence of comorbidity and impact on survival among persons with lung, colorectal, breast, or prostate cancer. Cancer 2014; 120: 1290-1314.

52 Grose D, Morrison DS, Devereux G, et al. The impact of comorbidity upon determinants of outcome in patients with lung cancer. Lung Cancer 2015; 87: 186-192.

53 Islam KM, Jiang X, Anggondowati T, et al. Comorbidity and survival in lung cancer patients. Cancer Epidemiol Biomarkers Prev 2015; 24: 1079-1085.

54 Luchtenborg M, Jakobsen E, Krasnik M, et al. The effect of comorbidity on stage-specific survival in resected non-small cell lung cancer patients. Eur J Cancer 2012; 48: 3386-3395.

55 Charlson ME, Pompei P, Ales KL, et al. A new method of classifying prognostic comorbidity in longitudinal studies: development and validation. J Chronic Dis 1987; 40: 373-383.

56 Piccirillo JF CI, Claybour P, Borah AJ, et al. The measurement of comorbidity by cancer registries. J Registry Manag 2003; 30: 8-14.

57 Sangha O, Stucki G, Liang MH, et al. The Self-Administered Comorbidity Questionnaire: a new method to assess comorbidity for clinical and health services research. Arthritis Rheum 2003; 49: 156-163.

58 Koller M, Warncke S, Hjermstad MJ, et al. Use of the lung cancer-specific quality of life questionnaire EORTC QLQ-LC13 in clinical trials: a systematic review of the literature 20 years after its development. Cancer 2015; 121: $4300-4323$.

59 Koller M, Hjermstad MJ, Tomaszewski KA, et al. An international study to revise the EORTC questionnaire for assessing quality of life in lung cancer patients. Ann Oncol 2017; 28: 2874-2881.

60 European Society for Medical Oncology. Designated Centres of Integrated Oncology and Palliative Care Application 2016. http://esmo.org/Patients/Designated-Centres-of-Integrated-Oncology-and-Palliative-Care Date last accessed: November 27, 2017.

61 Organisation of European Cancer Institutes. OECI Accreditation and Designation 2015. www.oeci.eu/ Attachments/OECI_ACC_Manual_2_0.pdf Date last accessed: November 27, 2017.

62 National Cancer Institute. NCI-Designated Cancer Centers 2017. www.cancer.gov/research/nci-role/cancer-centers Date last accessed: November 27, 2017.

63 Sullivan R. Has the US Cancer Centre model been "successful”? Lessons for the European cancer community. Mol Oncol 2009; 3: 192-203.

64 Bonnie J. Addario Lung Cancer Foundation. Centers of Excellence 2017. www.lungcancerfoundation.org/patients/ centers-of-excellence/ Date last accessed: November 27, 2017.

65 Calman K, Hine D. A Policy Framework for Commissioning Cancer Services. A Report by the Expert Advisory Group on Cancer to the Chief Medical Officers of England and Wales. London, Department of Health, 1995.

66 Lung Clinical Expert Group. 2017. National Optimal Lung Cancer Pathway. www.cancerresearchuk.org/sites/ default/files/national_optimal_lung_pathway_aug_2017.pdf Date last accessed: November 27, 2017.

67 Cancer Research UK. Lung Cancer Centres of Excellence 2017. www.cruklungcentre.org/ Date last accessed: November 27, 2017.

68 Khayat D. National cancer plans: the French experience. Am Soc Clin Oncol Educ Book 2013; 33: e242-e244.

69 The National Institute of Cancer, France. The Cancer Plan 2017-2019 http://en.e-cancer.fr/The-CancerPlan-2014-2019 Data last accessed: November 27, 2017. Date last updated: October 5, 2015.

70 Ukena DH H, Bischofsberger A, Ferencz J, et al. Lungenkrebszentren - Entwicklung und aktueller Status [Lung cancer centres - development and current status]. Pneumologe 2017; 14: 61-73.

71 OnkoZert. Informationen Zertifizierung Lungenkrebszentren [Certification information lung cancer centres]. http://onkozert.de/lungenkrebszentren.htm Date last accessed: November 27, 2017.

72 Deutsch Gesellschaft für Thoraxchirurgie. Kompetenzzentrum Thoraxchirurgie [Competent centres in thoracic surgery]. www.dgt-online.de/fuer-aerzte-kliniken/zertifizierung/ Date last accessed: November 27, 2017.

73 Deutsch Gesellschaft für Hämatologie und Medinzinische Onkologie. Zertifizierungen [Certification]. 2017. www. onkologie-zertifizierung.de/ Date last accessed: November 27, 2017.

74 Boyd J. Patient priorities project: lung cancer - consultation activities report. European Lung Foundation Internal Report 2015. Sheffield, European Lung Foundation, 2015.

75 European Lung Foundation. 2015. Patient priorities project: lung cancer - consultation activities report 2015 www.europeanlunginfo.org/lung-cancer/research-and-news/report-on-consultation-lung-cancer-patient-priorities-report Date last accessed: November 27, 2017.

76 Gamarra F, Noel JL, Brunelli A, et al. Thoracic oncology HERMES: European curriculum recommendations for training in thoracic oncology. Breathe 2016; 12: 249-255.

77 Meert AP, Noel JL, Gamarra F, et al. The thoracic oncology specialist: curriculum recommendations in thoracic oncology training. Eur Respir J 2016; 48: 628-631. 
78 Gamarra F, Boffetta P, De Ruysscher D, et al. Thoracic oncology HERMES syllabus: setting the basis for thoracic oncology training in Europe. Eur Respir J 2013; 42: 568-571.

79 Massard G, Antonoff MB, Noel JL, et al. Transatlantic editorial: thoracic surgeons need recognition of competence in thoracic oncology. Eur J Cardiothorac Surg 2017; 52: 611-615.

80 Massard G, Antonoff MB, Noel JL, et al. Transatlantic editorial: thoracic surgeons need recognition of competence in thoracic oncology. Ann Thorac Surg 2017; 104: 1103-1107.

81 Blum T, Schonfeld N. The lung cancer patient, the pneumologist and palliative care: a developing alliance. Eur Respir J 2015; 45: 211-226.

82 European Society of Radiology, American College of Radiology. European Society of Radiology (ESR) and American College of Radiology (ACR) report of the 2015 global summit on radiological quality and safety. Insights Imaging 2016; 7: 481-484.

83 Brunelli A, Charloux A, Bolliger CT, et al. The European Respiratory Society and European Society of Thoracic Surgeons clinical guidelines for evaluating fitness for radical treatment (surgery and chemoradiotherapy) in patients with lung cancer. Eur J Cardiothorac Surg 2009; 36: 181-184.

84 Brunelli A, Falcoz PE, D'Amico T, et al. European guidelines on structure and qualification of general thoracic surgery. Eur J Cardiothorac Surg 2014; 45: 779-786.

85 Matsuo Y, Onishi H, Nakagawa K, et al. Guidelines for respiratory motion management in radiation therapy. $J$ Radiat Res 2013; 54: 561-568.

86 Boily G, Filion E, Rakovich G, et al. Stereotactic ablative radiation therapy for the treatment of early-stage non-small-cell lung cancer: CEPO review and recommendations. J Thorac Oncol 2015; 10: 872-882.

87 Guckenberger $\mathrm{M}$, Andratschke $\mathrm{N}$, Alheit $\mathrm{H}$, et al. Definition of stereotactic body radiotherapy: principles and practice for the treatment of stage I non-small cell lung cancer. Strahlenther Onkol 2014; 190: 26-33.

88 Sahgal A, Roberge D, Schellenberg D, et al. The Canadian Association of Radiation Oncology scope of practice guidelines for lung, liver and spine stereotactic body radiotherapy. Clin Oncol (R Coll Radiol) 2012; 24: 629-639.

89 Kirkbride P, Cooper T. Stereotactic body radiotherapy. Guidelines for commissioners, providers and clinicians: a national report. Clin Oncol (R Coll Radiol) 2011; 23: 163-164.

90 Benedict SH, Yenice KM, Followill D, et al. Stereotactic body radiation therapy: the report of AAPM Task Group 101. Med Phys 2010; 37: 4078-4101.

91 De Ruysscher D, Faivre-Finn C, Moeller D, et al. European Organization for Research and Treatment of Cancer (EORTC) recommendations for planning and delivery of high-dose, high precision radiotherapy for lung cancer. Radiother Oncol 2017; 124: 1-10.

92 Potters L, Kavanagh B, Galvin JM, et al. American Society for Therapeutic Radiology and Oncology (ASTRO) and American College of Radiology (ACR) practice guideline for the performance of stereotactic body radiation therapy. Int J Radiat Oncol Biol Phys 2010; 76: 326-332.

93 Guckenberger M, Andratschke N, Dieckmann K, et al. ESTRO ACROP consensus guideline on implementation and practice of stereotactic body radiotherapy for peripherally located early stage non-small cell lung cancer. Radiother Oncol 2017; 124: 11-17.

94 European Association for Palliative Care. White Paper on Standards and Norms for Hospice and Palliative Care in Europe: part 1+2. www.eapcnet.eu/publications/Organisation/EAPCStandardsNorms Date last accessed: November 4, 2017.

95 European Commission. Aid Delivery Methods. Volume 1. Project Cycle Management Guidelines. Brussels, European Commission. 2004. https://ec.europa.eu/europeaid/sites/devco/files/methodology-aid-delivery-methodsproject-cycle-management-200403_en_2.pdf Date last accessed: November 27, 2017.

96 Blum TG, Schönfeld N, Jagota A, et al. Integration und Steuerfunktion klinischer Krebsregister in der onkologischen Versorgung [Integration and control function of clinical cancer registries in oncological care]. Forum 2012; 27: 431-435.

97 Russell GK, Jimenez S, Martin L, et al. A multicentre randomised controlled trial of reciprocal lung cancer peer review and supported quality improvement: results from the improving lung cancer outcomes project. $\mathrm{Br} J$ Cancer 2014; 110: 1936-1942. 